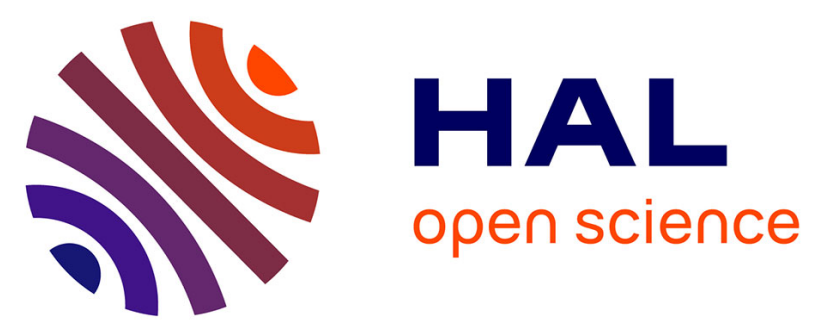

\title{
Ecofriendly lignocellulose pretreatment to enhance the carboxylate production of a rumen-derived microbial consortium
}

Adèle Lazuka, Cécile Roland, Abdellatif Barakat, Fabienne Guillon, Michael O’Donohue, Guillermina Hernandez Raquet

\section{To cite this version:}

Adèle Lazuka, Cécile Roland, Abdellatif Barakat, Fabienne Guillon, Michael O’Donohue, et al.. Ecofriendly lignocellulose pretreatment to enhance the carboxylate production of a rumen-derived microbial consortium. Bioresource Technology, 2017, 236, pp.225-233. 10.1016/j.biortech.2017.03.083 . hal-01607636

\section{HAL Id: hal-01607636 \\ https://hal.science/hal-01607636}

Submitted on 25 May 2020

HAL is a multi-disciplinary open access archive for the deposit and dissemination of scientific research documents, whether they are published or not. The documents may come from teaching and research institutions in France or abroad, or from public or private research centers.
L'archive ouverte pluridisciplinaire HAL, est destinée au dépôt et à la diffusion de documents scientifiques de niveau recherche, publiés ou non, émanant des établissements d'enseignement et de recherche français ou étrangers, des laboratoires publics ou privés. 


\section{Accepted Manuscript}

Ecofriendly lignocellulose pretreatment to enhance the carboxylate production of a rumen-derived microbial consortium

Adèle Lazuka, Cécile Roland, Abdellatif Barakat, Fabienne Guillon, Michael O'Donohue, Guillermina Hernandez-Raquet

PII:

DOI:

Reference:

To appear in:

Received Date:

Revised Date:

Accepted Date:
S0960-8524(17)30355-3

http://dx.doi.org/10.1016/j.biortech.2017.03.083

BITE 17787

Bioresource Technology

18 December 2016

11 March 2017

13 March 2017

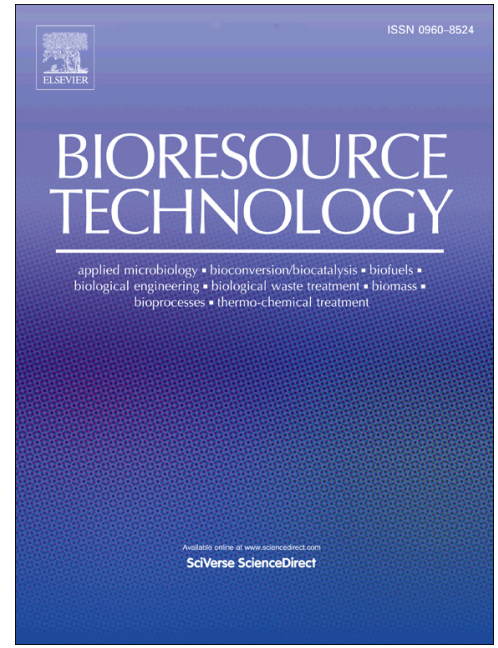

Please cite this article as: Lazuka, A., Roland, C., Barakat, A., Guillon, F., O'Donohue, M., Hernandez-Raquet, G., Ecofriendly lignocellulose pretreatment to enhance the carboxylate production of a rumen-derived microbial consortium, Bioresource Technology (2017), doi: http://dx.doi.org/10.1016/j.biortech.2017.03.083

This is a PDF file of an unedited manuscript that has been accepted for publication. As a service to our customers we are providing this early version of the manuscript. The manuscript will undergo copyediting, typesetting, and review of the resulting proof before it is published in its final form. Please note that during the production process errors may be discovered which could affect the content, and all legal disclaimers that apply to the journal pertain. 
1 Ecofriendly lignocellulose pretreatment to enhance the carboxylate production of a

2 rumen-derived microbial consortium.

3 Adèle Lazuka ${ }^{1,2,3}$, Cécile Roland ${ }^{1,2,3}$, Abdellatif Barakat ${ }^{4}$, Fabienne Guillon ${ }^{5}$, Michael

4 O’Donohue ${ }^{1,2,3}$, Guillermina Hernandez-Raquet ${ }^{1,2,3^{*}}$

$5 \quad{ }^{1)}$ Université de Toulouse, INSA, UPS, LISBP, 135 Avenue de Rangueil, F-31077 Toulouse

6 Cedex 4, France

$7 \quad{ }^{2)}$ INRA, UMR792 Ingénierie des Systèmes Biologiques et des Procédés, F-31400 Toulouse,

8 France

$9 \quad{ }^{3)}$ CNRS, UMR5504, F-31400 Toulouse, France

10 4) UMR IATE, CIRAD, Montpellier SupAgro, INRA, Université de Montpelier, 34060,

11 Montpellier, France.

$12{ }^{5)}$ Centre de Recherche Agro-alimentaire de Nantes, INRA, Rue de la Géraudière, 71627 ,

13 44316, Nantes-03, France

14 "LAZUKA Adèle" lazuka@insa-toulouse.fr

15 "Cécile Roland" roland@insa-toulouse.fr

16 "BARAKAT Abdellatif" barakat@ supagro.inra.fr

17 " GUILLON Fabienne" Fabienne.Guillon@ nantes.inra.fr

"O’DONOHUE Michael" michael.odonohue@ insa-toulouse.fr

19 * Corresponding author: Guillermina Hernandez-Raquet, Laboratoire d'Ingénierie des

20 Systèmes Biologiques et des Procédés UMR5504, UMR792, CNRS, INRA, INSA, 135

21 avenue de Rangueil, 31077 Toulouse Cedex 04, France. Tel: + 33 (0) 5615599 77. Fax: + 33

225615597 60. Email: hernandg@insa-toulouse.fr 


\section{Abstract}

Innovative dry chemo- and chemo-mechanical pretreatments form an interesting approach for modifying the native physico-chemical composition of lignocellulose facilitating its microbial conversion to carboxylates. Here, the impact of four dry-pretreatment conditions on the microbial transformation of wheat straw was assessed: milling to $2 \mathrm{~mm}$ and $100 \mu \mathrm{m}$, and $\mathrm{NaOH}$ chemical impregnation at high substrate concentrations combined with milling at 2 $\mathrm{mm}$ and $100 \mu \mathrm{m}$. Pretreatment effect was assessed in the light of substrate structure and composition, its impact on the acidogenic potential and the major enzyme activities of a rumen-derived microbial consortium RWS. Chemo-mechanical pretreatment strongly modified the substrate macroporosity. The highest carboxylate production rate was reached after dry chemo-mechanical treatment with $\mathrm{NaOH}$ at $100 \mu \mathrm{m}$. A positive impact of the dry chemo-mechanical treatment on xylanase activity was observed also. These results underline that increasing substrate macroporosity by dry chemo-mechanical pretreatment had a positive impact on the microbial acidogenic potential.

Keywords: lignocellulose bioconversion; anaerobic microbial consortium; carboxylate production; enzymes; dry chemo-mechanical pretreatment. 


\section{Introduction}

For over three decades intense R\&D activity has focused on the development of industrial processes to convert lignocellulosic (LC) biomass into fuels, energy and value added chemicals, using various combinations of mechanical, chemical and bioconversion technologies (Kim and Dale, 2004). Among the manufacturing routes that have been investigated, the carboxylate platform is rather attractive (Agler et al., 2011). Operating under non-sterilized, non-aerated conditions, the carboxylate platform exploits the robustness and large enzymatic potential of mixed microbial communities for the transformation of LC biomass into carboxylates (Agler et al., 2011). In this platform, microbial communities hydrolyze the LC biomass producing soluble oligomeric and monomeric compounds that are further transformed into short chain carboxylates (or volatile fatty acids - VFA) by acidogenic and acetogenic microorganisms. In this respect, the carboxylate platform is related to the biogas platform, a two-stage anaerobic digestion system that produces carboxylates as intermediates that are then broken down by methanogenic archaea into methane. However, in the carboxylate platform, the products are considered to be building blocks for the production of added value chemicals and materials (e.g polyhydroxyalcanoate bioplastics), and liquid biofuels (Agler et al, 2011; Torella et al, 2013), rather than intermediates for low value renewable energy (i.e. bio- $\mathrm{H}_{2}$, and bio- $\mathrm{CH}_{4}$ ), which is inevitably in direct competition with low-priced fossil resources, such as shale gas.

Despite its attractive features, the carboxylate platform is nonetheless limited by the ability to extract fermentable components from LC biomass, which constitutes a highly recalcitrant raw material. Indeed, LC biomass is a composite material composed mainly of cellulose, hemicellulose and lignin. Together, these polymers and other minor components, form a chemically- and structurally-complex, three dimensional matrix that is particularly resistant to both abiotic and biotic aggression. The structural and protective role played by LC-based 
64

structures in plants prevents their destruction by microorganisms and their enzymes (Mosier et al., 2005). To overcome LC biomass recalcitrance, various types of strategies involving a pretreatment step have been investigated (Alvira et al., 2010; Hendriks and Zeeman, 2009). In this case, chemical and/or physical processes are first used to increase the accessible surface area and porosity of LC biomass, thus rendering it more amenable to the subsequent action of biocatalytic agents (Hendriks and Zeeman, 2009; Mosier et al., 2005). Despite the development of numerous pretreatments, cost effectiveness still has to be achieved, notably by reducing non-specific effects and energy expenditure and maximizing beneficial effects for the subsequent biocatalytic processes.

The effect of different pretreatments on LC biomass has been extensively studied (Alvira et al., 2010; Hendriks \& Zeeman, 2009; Mosier et al., 2005), revealing that each type of pretreatment is characterized by advantages and disadvantages. For example, chemical treatments often generate fermentation inhibitors while mechanical methods are usually associated with high energy expenditure (Barakat et al., 2013; Jönsson et al., 2013). However, the absolute need for pretreatment is cleverly illustrated by the truism "the only process more expensive than pretreatment is no pretreatment' (Wyman, 2007).

Among the vast array of LC biomass pretreatments that have been tested, alkaline pretreatment using sodium hydroxide is one of the most effective and attractive methods. It presents a high capacity for delignification, disrupts the biomass structure and increases porosity, thus making cellulose and hemicellulose more accessible, but with low sugar degradation (Kaar and Holtzapple, 2000; Mathew et al., 2011; Zhao et al., 2008). Some form of particle size reduction using mechanical methods also usually forms part of pretreatment technologies (Hendriks and Zeeman, 2009), because it is required to increase biomass surface area and can improve depolymerization and reduces residual waste (Barakat et al., 2014; Palmowski and Müller, 2000). 
Recently, innovative procedures so-called 'dry chemical' (DC) and 'dry chemo-mechanical' (DCM) pretreatments have been developed to reduce energy consumption (Miao et al., 2011, Barakat et al., 2013). DC pretreatment consists of moderate chemical treatment using alkali impregnation of LC biomass at high solids loadings, while dry-chemo-mechanical pretreatment describes a process in which dry chemical pretreatment is performed simultaneously with mechanical particle size reduction (Barakat et al., 2014). Advantageously, these pretreatments reduce the use of chemicals and energy demand, enhance polysaccharide saccharification when using enzyme cocktails (Barakat et al., 2014) and, thanks to high solids loadings, permit process intensification and reactor downsizing. To investigate whether DC and DCM pretreatments can be beneficial for the carboxylate platform, we have investigated the use of these technologies in combination with anaerobic conversion of wheat straw using a lignocellulolytic cow rumen-derived microbial consortium (RWS). The effect of the pretreatments on the subsequent microbial activity has been investigated, monitoring the kinetics of LC biomass conversion, carboxylate production and the dynamics of key enzymatic activities. Our findings reveal that DC pretreatment increased the initial VFA production rate and that this increase was most pronounced when DCM pretreatment was employed. This increase was accompanied by an increase in early phase xylanase activity, but CMCase activity was unchanged. Finally, our results indicate a correlation between lignocellulose macroporosity and its degradability by a hydrolytic microbial consortium.

\section{Materials and methods}

\subsection{Wheat straw}

A $20 \mathrm{~kg}$ batch of wheat straw (Koreli variety grown on an INRA-owned experimental farm, Boissy-le-Repos, France) was harvested (in August 2011), milled to $2 \mathrm{~mm}$ using a knife mill 
113 (Retsch SM 100, Germany) and stored at room temperature $\left(20-25^{\circ} \mathrm{C}\right)$ until use as the for all

114 the experiments, hereafter referred to as $2 \mathrm{~mm}$ wheat straw (biomass A).

115 2.2. Dry chemical pretreatment

116 Sodium hydroxide $(\mathrm{NaOH})$ was dissolved in distilled water $(5 \mathrm{~g}$ in $20 \mathrm{~mL})$. Wheat straw at 2

$117 \mathrm{~mm}(100 \mathrm{~g})$ was impregnated during $5 \mathrm{~h}$ at ambient conditions $\left(25^{\circ} \mathrm{C}\right)$ with this alkaline

118 solution using a pulverizing system ( $5 \mathrm{~g}$ of $\mathrm{NaOH}$ per $100 \mathrm{~g}$ of wheat straw) according to the

119 procedure described previously (Barakat et al., 20014). The chemically treated wheat straw-

$1202 \mathrm{~mm}$ was dried at $105{ }^{\circ} \mathrm{C}(12 \mathrm{~h})$ resulting in a final moisture content of $8-10 \%(\mathrm{w} / \mathrm{w})$ and

121 designated biomass $\mathrm{B}$.

122 2.3. Mechanical treatment

123 Biomass A and B were comminuted using an impact mill operating at ambient temperature and 18,000 rpm (Hosokawa-alpine, type UPZ, Augsburg, Germany). Fine particulate fractions were collected using a $100 \mu \mathrm{m}$ mesh (the material was milled until it passed through the grid) and designated as biomass $\mathrm{C}$ and $\mathrm{D}$, respectively.

2.4. Substrate characterization

\subsubsection{Substrate composition}

For compositional analysis wheat straw $(40 \mathrm{mg}$ ) was submitted to the sulfuric acid hydrolysis method described by de Souza et al. (2013), analyzing monosaccharides (glucose, xylose and arabinose) by high-performance liquid chromatography (HPLC) using an Ultimate 3000

132 Dionex separation system equipped with a BioRad Aminex HPX 87H affinity column and a

133 refractive index detector (Thermo Scientific). The protocol used for HPLC analysis was that 134 described elsewhere (Monlau et al., 2012).

Lyophilized wheat straw samples were also analyzed by Fourier transform infrared 
$157 \quad \mathrm{D}=\frac{4 \mathrm{~S}}{\Delta \mathrm{P}}($ Eq. 1)

detector, following the procedure described by Lazuka et al. (2015). For FT-IR spectral analysis, the peak ratio $1512: 1375 \mathrm{~cm}^{-1}$ was considered representative of the lignin:holocellulose ratio, while peaks at $1430 \mathrm{~cm}^{-1}$ and $898 \mathrm{~cm}^{-1}$ were attributed to crystalline and amorphous cellulose respectively (Monlau et al., 2012), and the ratio of these peaks was considered to be the lateral order index (LOI), which represents the ratio of crystalline:amorphous cellulose.

\subsubsection{Determination of particle size and energy consumption}

Particle size was analyzed by laser granulometry using a Mastersizer 2000 (Malvern Instruments, Orsay, France).

The energy consumed during milling was determined in triplicates using a watt meter following a previously described procedure (Barakat el al., 2014).

\subsubsection{Determination of macroporosity by suction pressure}

Macroporosity of the four treated wheat straw samples (A-D) was determined by measuring the water-absorption kinetics at different osmotic pressures (Robertson and Eastwood, 1981). The water retention capacity (macroporosity profile) was obtained by dialysis of hydrated wheat straw samples using three solutions of polyethylene glycol (PEG) (MW $10,000)$ at 10,75 and 100 g. $\mathrm{L}^{-1}$ inducing a known suction pressure $(0.009,0.112$ and $0.206 \mathrm{MPa}$, respectively). The water retained by the fiber matrix was related to pore size through suction pressure and surface tension according to equation 1: where $\mathrm{D}(\mathrm{mm})$ is the pore diameter, $\mathrm{S}$ the solute (water) surface tension, $\Delta \mathrm{P}$ the suction pressure $(\mathrm{MPa})$ used to measure the ratio water held:pore volume.

Water absorption at different suction pressures (used to explore different pore diameters) was

161 determined by presoaking wheat straw samples overnight at $4{ }^{\circ} \mathrm{C}$, and transferring the 
$32 \mathrm{~mm}$ diameter, Visking R dialysis bag, PolyLabo, Strasbourg, France). The dialysis bags were then sealed and placed in a $100 \mathrm{~mL}$ PEG solution and shaken overnight at $37^{\circ} \mathrm{C}$ $\left(100\right.$ cycles. $\left.\min ^{-1}\right)$. The content of the dialysis bags was weighed accurately then dried overnight $\left(100^{\circ} \mathrm{C}\right)$ to determine dry weight and water content. Each wheat straw sample at each PEG concentration was tested in triplicate. Results ( $\mathrm{g}$ water $\mathrm{g}^{-1}$ dry sample) represented the difference between the total pore volume (estimated at $10 \mathrm{~g} / \mathrm{L} \mathrm{PEG)}$ and the volume of 1 $\mu \mathrm{m}$-diameter pores (estimated at $100 \mathrm{~g} / \mathrm{L} \mathrm{PEG),} \mathrm{which} \mathrm{constitute} \mathrm{the} \mathrm{pore} \mathrm{volume} \mathrm{with}$ diameter $>1 \mu \mathrm{m}$ likely to be accessible to bacteria. After presoaking, the liquid fraction was collected and the neutral sugar content was evaluated using a Skalar autoanalyzer (Skalar, Breda, Netherlands), employing the sulfuric orcinol method (Tollier and Robin, 1979).

\subsubsection{Saccharification with commercial enzymes}

Saccharification of the four treated wheat straw samples, A to D, was evaluated using a commercial enzymatic mixture (Celluclast $1.5 \mathrm{~L}$ Novozyme). Dry wheat straw $(1 \%, \mathrm{w} / \mathrm{w})$ was incubated for $72 \mathrm{~h}$ at $50^{\circ} \mathrm{C}$ with 20 FPU.g ${ }^{-1} \mathrm{dw}$ cellulase supplemented with $81 \mathrm{U}^{\mathrm{mL}} \mathrm{m}^{-1} \beta$ glucosidase (Novozyme 188) in $50 \mathrm{mM}$ sodium acetate buffer (pH 5.0) containing 0.5 g.L $\mathrm{L}^{-1}$ sodium azide. Following centrifugation $\left(7197 \mathrm{~g}, 10 \mathrm{~min}\right.$ at $\left.4^{\circ} \mathrm{C}\right)$, the reducing sugar content in the supernatant was quantified using the di-nitro-salicylic acid method (DNS).

\subsection{Lignocellulose bioconversion by RWS in anaerobic reactors}

Microbial bioconversion of LC substrate by a cow-rumen derived consortium (RWS) that displays a good ability to degrade wheat straw was carried out in anaerobic batch reactors ( $2 \mathrm{~L}$ BIOSTAT $^{\circledR} \mathrm{A}+$, Sartorius, Germany). Bioreactors containing wheat straw samples (A to D) as the sole carbon source $\left(20 \mathrm{~g} . \mathrm{L}^{-1}\right)$ suspended in mineral medium (Lazuka et al., 2015). The bioreactors were operated under agitation $(300 \mathrm{rpm})$ at a mesophilic temperature $\left(35^{\circ} \mathrm{C}\right)$ and $\mathrm{pH}(6.15)$, which was adjusted by the appropriate addition of $\mathrm{H}_{3} \mathrm{PO}_{4}$ at the beginning of the experiment (before inoculation) and thereafter regulated by the automated addition of $1 \mathrm{M}$ 
$\mathrm{NaOH}$, according to the protocol established by Lazuka et al., (2015). Each microbial bioconversion reactor was performed in biological duplicates over a 15-day period. Wheat straw removal, residual substrate compositional analysis, total organic carbon (TOC), VFA production and enzymatic activities were monitored throughout the incubation period.

\subsection{Chemical analyses}

To quantify total solids (TS) $10 \mathrm{~mL}$ samples were removed, centrifuged (7197 x $g, 10 \mathrm{~min}$, $\left.4^{\circ} \mathrm{C}\right)$, rinsed twice with distilled water and dried $24 \mathrm{~h}$ at $105^{\circ} \mathrm{C}$. For the mineral fraction $(\mathrm{MF})$, mineralization was performed at $500^{\circ} \mathrm{C}$ for $2 \mathrm{~h}$, and volatile solids (VS) were estimated from the difference between TS and MF. VS degradation was expressed as weight/weight percentages.

The composition of the residual substrate in the reactor was characterized as described above for substrate characterization (section 2.4.1).

VFA production was monitored using a Varian 3900 gas chromatograph as described by Cavaillé et al. (2013). The total organic carbon (TOC) content of the liquid fraction was measured using a TOC analyzer (TOC-V $\mathrm{V}_{\mathrm{CSN}}$, Shimadzu Co., Japan). Gas composition was analyzed using an HP 5890 gas chromatograph equipped with a conductivity detector and a HAYSEP D column. All chemical measurements were done in technical duplicates.

All the macro-kinetic parameters are expressed as average values obtained from duplicate biological reactors (biological duplicates). Smoothed data and derivatives were obtained after polynomial regression on the raw data. The statistical significance of differences between the types of pretreatment was evaluated by one-way ANOVA $(\mathrm{P}<0.05)$ for characterization parameters (LOI, macroporosity, saccharification, composition).

\subsection{Enzyme activity assays}

To measure enzyme activity, triplicate samples $(5 \mathrm{~mL})$ were withdrawn at regular intervals and centrifuged $\left(7197 \mathrm{x} g, 10 \mathrm{~min}, 4^{\circ} \mathrm{C}\right)$ yielding a supernatant and a sonicated solid pellet 
213 fraction as described by Lazuka et al. (2015). These two fractions were considered to be

214 representative of extracellular (supernatant), and sum of intracellular and cell-bound

215 (sonicated pellet) localizations respectively. For each reactor and each sampling time, end-

216 point enzymatic activities were measured in technical duplicates in both the extracellular and

217 the intracellular and cell-bound fractions. All enzymatic activities were expressed as averages

218 of the two values obtained from the duplicate reactors.

219 Xylanase and endoglucanase (CMCase) activity were measured using $1 \% \mathrm{w} / \mathrm{v}$ xylan

220 beechwood (Sigma) and 1\% w/v carboxymethyl cellulose (CMC) (Sigma) respectively

221 according to the previously described protocol (Lazuka et al., 2015). One unit of CMCase or 1

222 unit of xylanase activity (UA, unit of activity) was defined as the amount of enzyme that

223 produces $1 \mu \mathrm{mol}$ of reducing sugars per minute.

\section{Results and discussion}

225 The impact of dry pretreatment on the kinetics of wheat straw degradation and carboxylate

226 production by a microbial consortium RWS was assessed using four different pretreated

227 wheat straws. Samples A and C were milled to $2 \mathrm{~mm}, \mathrm{~B}$ and D to $100 \mu \mathrm{m}$, and C and D were

228 submitted to $5 \%(\mathrm{w} / \mathrm{w}) \mathrm{NaOH}$ impregnation at high LC solids. These conditions facilitated the

229 assessment of a possible synergy between dry milling and chemical pretreatment. Moreover,

230 it is important to underline that $\mathrm{D}$ was first chemically pretreated and then milled, because this

231 sequence is expected to reduce the energy demand associated with milling and increase

232 biomass component extractability (Barakat et al., 2014).

233 3.1. Characterization of the pretreated wheat straw

234 The energy consumption associated with the production of A was $223.3 \mathrm{~kJ} \mathrm{~kg}^{-1}$, while the

235 production of B required 2.8 times more energy (Table1). The energy demand associated with

236 the production of $\mathrm{C}$ was the same as that for $\mathrm{A}$, which is logical since chemical impregnation

237 was carried out after milling. However, energy consumption associated with the production of 
$\mathrm{D}(100 \mu \mathrm{m})$ was almost half that required to produce $\mathrm{B}$, which clearly demonstrates that prior chemical pretreatment was beneficial. It is likely that during $\mathrm{NaOH}$ impregnation, the lignocellulosic matrix is weakened and disintegrated into finer components, thus increasing overall energetic efficiency (Kaar and Holtzapple, 2000; Mathew et al., 2011; Zhao et al., 2008; Barakat et al., 2014).

In order to identify the biomass features that affect microbial bioconversion, samples A to D were characterized with regard to four parameters: (i) the LOI which gives insight into substrate crystallinity; (ii) the $1 \mu \mathrm{m}$-pore volume or macroporosity, considered as the volume accessible to bacteria (Guillon et al., 1998); (iii) biochemical composition in terms of cellulose, hemicellulose and lignin $(\mathrm{C}, \mathrm{H}, \mathrm{L})$ and (iv) the enzymatic saccharification under standard conditions. Figure 1A shows that particle size had no significant impact on wheat straw crystallinity (LOI), irrespective of the substrate pretreatment. However, chemical pretreatment decreased LOI from $0.766 \pm 0.079$ (mean of A and B substrates, without chemical pretreatment) to $0.572 \pm 0.05$ (mean of $C$ and D substrates, with chemical pretreatment), irrespective of particle size. Regarding the impact of $\mathrm{NaOH}$ pretreatment on cellulose crystallinity, previous studies have provided contradictory results. For instance, when applying DCM, soda pretreatment to wheat straw at a particle size below $60 \mu \mathrm{m}$, Barakat et al. (2014) obtained an $11 \%$ increase in crystallinity. This result was attributed to the solubilization of amorphous polymers and not to an actual increase in crystallinity. In fact, several parameters can impact cellulose crystallinity, notably the severity of a given treatment. Bali et al. (2015) showed that the cellulose crystallinity of alkali-pretreated Populus varied as function of severity. The authors showed that shorter pretreatments (lower severity) reduced cellulose crystallinity, probably through the actual disruption of the cellulose crystalline structure. However, in the same study, it was reported that crystallinity increased when the pretreatment was prolonged, this observation being attributed to the 
263

264

265

266

267

268

269

270

271

272

273

274

275

276

277

278

279

280

281

282

283

284

285

286

287

solubilization of the amorphous cellulose component. The results obtained in the present

study are consistent with the hypothesis that $\mathrm{NaOH}$ pretreatment causes the cellulose to swell and decreases cellulose crystallinity, as described by Agbor et al. (2011), suggesting that the severity of the applied treatment did not induce any rise in crystallinity.

The comparison of the macroporosity of samples A to D (Fig. 1B) revealed a negative correlation between macroporosity with fine milling $(100 \mu \mathrm{m})$ in the absence of chemical pretreatment. For sample B, macroporosity was $1.5 \pm 0.3 \mathrm{~g} \cdot \mathrm{g}^{-1}$, which is lower than that measured for A, $2.9 \pm 0.4 \mathrm{~g} \cdot \mathrm{g}^{-1}$. On the other hand, soda pretreatment had a positive effect on macroporosity, reaching $4.4 \pm 0.9 \mathrm{~g} . \mathrm{g}^{-1}$ and $4.6 \pm 0.6 \mathrm{~g} \cdot \mathrm{g}^{-1}$ for samples $\mathrm{C}$ and $\mathrm{D}$, respectively. These results suggest that milling to $100 \mu \mathrm{m}$ (B) actually reduced accessibility to bacteria, whereas chemical pretreatment (i.e. samples C and D) increased it. In early studies on resistant starch dietary fiber, a correlation between macroporosity (generally in the range 1 and $10 \mathrm{~g} . \mathrm{g}^{-1}$ ) and substrate fermentability was described (Guillon et al., 1998; Robertson et al., 2000). Consistently, in the present study, macroporosity was shown to be correlated to the quantity of fermentable sugars formed by pretreatment, with samples $\mathrm{C}$ and $\mathrm{D}$ displaying the highest amounts of soluble neutral sugars $\left(1.705 \pm 0.003 \mathrm{mg} . \mathrm{L}^{-1}\right.$ and $2.394 \pm 0.003 \mathrm{mg} . \mathrm{L}^{-1}$, respectively), while non-chemically treated substrates displayed lower levels $(0.948 \pm 0.004$ mg. $\mathrm{L}^{-1}$ and $0.682 \pm 0.003 \mathrm{mg} . \mathrm{L}^{-1}$ for substrates $\mathrm{A}$ and $\mathrm{B}$, respectively).

The biochemical analysis of the four wheat straw samples revealed no significant compositional changes after pretreatment, with the average composition being (in $\% \mathrm{w} / \mathrm{w}$ ) 43.6 $\pm 3.4 \%$ cellulose, $23.2 \pm 1.4 \%$ hemicellulose and $19.7 \pm 1.7 \%$ lignin (Fig. 1C), values that are similar to those measured in the raw substrate. This compositional stability can be explained by the fact that no extraction was performed, meaning that solubilized components remained in the sample, and also indicates that very little biomass loss occurred, consistent with the findings of Barakat et al. (2014). Carbon loss is often associated with alkaline 
288

289

290

291

292

293

294

295

296

297

298

299

300

301

302

303

304

305

306

307

308

309

310

311

312

pretreatments and occurs in the form of carbon dioxide release associated with peeling

reactions. This phenomenon is highly correlated with the pretreatment severity factor and substrate recalcitrance (Hendriks and Zeeman, 2009; Karp et al., 2015). Therefore, the results obtained on the biochemical composition of LC before and after pretreatment indicate that the pretreatments used in this study are relatively mild, ensuring good mass conservation.

Enzymatic saccharification of the four pretreated materials (Fig. 1D) did not reveal any clear correlations between particle size and substrate accessibility to enzyme hydrolysis. However, soda treatment clearly enhanced the enzymatic release of reducing sugars, since on the dry chemo-mechanical pretreatment (D) the release of soluble reducing sugars was 2-fold higher when compared to A and B (no soda treatment) and approximately 1.2-fold higher than that obtained with C, consistent with previous findings (Barakat et al. 2014).

In conclusion, assuming that cellulose crystallinity, the aptitude towards enzymatic saccharification and macroporosity are reliable indicators of pretreated substrate accessibility for microbial bioconversion, it appears reasonable to suggest that samples C and D should be readily amenable to bioconversion by suitable microbial consortia. In this regard, considering samples A and B, which had not been submitted to soda treatment, the only clear difference concerned their macroporosity (lower for B). This makes prediction more difficult, but suggests that $\mathrm{B}(100 \mu \mathrm{m}$ particle size $)$ might be less amenable to microbial bioconversion. 3.2. Fermentation of the pretreated wheat straw by the microbial consortium RWS 3.2.1 Wheat straw degradation and VFA production by RWS Wheat straw A to D were anaerobically fermented by the RWS consortium. The biochemical analysis of residual wheat straw revealed that only the holocellulose fraction was degraded, irrespective of the pretreatment applied, meaning that the lignin concentration was unchanged throughout the experiment (average lignin concentration of $4.35 \pm 0.55 \mathrm{~g} . \mathrm{L}^{-1}$ for all reactors and sampling times, representing $21.7 \pm 2.75 \% \mathrm{w} / \mathrm{w}$ of the initial substrates; data not show). 
313

314

315

316

317

318

319

320

321

322

323

324

325

326

327

328

329

330

331

332

333

334

335

336

337

Therefore, subsequently wheat straw degradation was expressed more simply as the

percentage of holocellulose-related carbon (in moles) removal (expressed as percentage of the initial holocellulose-related carbon content, $\%$ iCmol $\left._{\text {Holo }}\right)$.

In this respect, the results obtained for holocellulose removal (\% iCmolHolo) on samples $\mathrm{A}, \mathrm{C}$ and $\mathrm{D}$ at the end of the experiment were similar with removal values of $64.2 \pm 1.0,68.8 \pm 3.4$ and $58.2 \pm 5.4 \%$, respectively (Fig. 2A). As predicted by the macroporosity analysis, despite the larger surface area available in B, this sample was less apt for bioconversion by the RWS consortium (37.0 $\pm 1.1 \%$ of holocellulose removed at the end of the experiment). Likewise, measurement of specific VFA production (expressed as moles of carbon of VFA produced per mole of carbon of the initial holocellulose, $\mathrm{Cmol}_{\mathrm{VFA}} . \mathrm{iCmol}^{-1}{ }_{\mathrm{Holo}}$ ) revealed a similar trend. Maximal VFA production levels (approximately $0.45 \mathrm{Cmol}_{\text {VFA. }} \mathrm{iCmol}^{-1}{ }_{\text {Holo }}$ ) were obtained with A, C and D at the end of the incubation, whereas significantly lower VFA production was recorded for $\mathrm{B}\left(0.31 \pm 0.02 \mathrm{Cmol}_{\mathrm{VFA}} . \mathrm{iCmol}^{-1} \mathrm{Holo}\right)($ Fig. $2 \mathrm{~B})$. Accordingly, the holocellulose degradation and VFA production rates (Fig. 2C and D) displayed similar trend for each substrate but the maximal value and time needed to reach such maximum value varied importantly in function of the pretreatment applied. Comparing these specific rates for the different pretreated substrates, it is noteworthy that the highest rates for hollocellulose degradation and VFA production were obtained after DCM pretreatment (sample D), DC pretreatment being the next best option (sample C). Indeed, with these samples, hollocellulose degradation reached a maximum at an earlier stage in the experiment (i.e. 12 and $14.6 \%$ $\mathrm{iCmol}^{-1}{ }_{\text {Holo. }}$ day $^{-1}$ after 3.5 and 2.8 days for $\mathrm{C}$ and $\mathrm{D}$, respectively) whereas maximum degradation rate was lower and occurred later for A and even more for B (i.e. 7.6 and $4 \%$ $\mathrm{iCmol}^{-1}$ Holo.day ${ }^{-1}$ after 4.8 and 5.2 days for A and B, respectively). Likewise, the highest VFA production rates were also measured for $\mathrm{C}$ and $\mathrm{D}\left(0.066\right.$ and $0.094 \mathrm{Cmol}_{\mathrm{VFA}} . \mathrm{iCmol}^{-1}{ }_{\text {Holo. }}$ day ${ }^{-1}$, respectively), with maximum production being reached after 2.5 days. In contrast, with 
samples A and B, VFA production peaked after 5 days, with rates reaching only 0.045 and $0.028 \mathrm{Cmol}_{\mathrm{VFA}} \cdot \mathrm{iCmol}^{-1}{ }_{\mathrm{Holo}} \cdot \mathrm{day}^{-1}$, respectively. Overall, these results underline the beneficial effect of the soda treatment, particularly when it was coupled to mechanical milling to $100 \mu \mathrm{m}$.

Compared to the fermentation of $2 \mathrm{~mm}$ wheat straw (sample A), the VFA, $\mathrm{CO}_{2}$ and $\mathrm{H}_{2}$ yields increased when chemically-pretreated substrates were used (Table 2). The highest yields were systematically obtained after DCM pretreatment (sample D), while the fermentation of samples B and C procured intermediate values.

The composition of the carboxylates produced at the end of the experiment (Table 2), was for all samples mostly acetic, propionic and butyric acids, with minor quantities of valeric and hexanoic acids. Quantification of TOC level in the supernatant corresponded to the VFA concentration (data not shown) indicated that no other metabolites were produced. The main difference was observed for chemically-treated samples C and D. The fermentation of these substrates procured a higher amount of butyric acid, which was associated with a lower level of acetic acid. It is known that members of the Clostridia genus are able to ferment hexoses into acetate, and xylose into butyrate and dihydrogen (Jaros et al., 2013; Liu and Yang, 2006; Raganati et al., 2014). Furthermore, it is known that alkaline pretreatment efficiently removes hemicellulose from LC biomass (Hendriks and Zeeman, 2009). Since Clostridia is one of the main microbial groups found in RWS (Lazuka et al., 2015), it is possible that a metabolic shift from acetate (from glucose) to butyrate (from xylose) pathway in this microbial group induced a higher proportion of butyrate in soda treatment conditions. Nevertheless, to confirm such a hypothesis, further characterization of the microbial community's composition during incubation time will be needed.

Regarding particle size, it is often assumed that size reduction facilitates substrate accessibility to enzymes and microorganisms. However, herein we show that extremely fine 
milling (i.e. to $100 \mu \mathrm{m}$ ) has an adverse effect on biodegradation and VFA production. This

result could be attributed to the liberation of inhibitory compounds or to an increase in recalcitrance due to pretreatment severity. However, as discussed above, LOI results revealed that crystallinity did not increase. Moreover, it is unlikely that mechanical milling would generate inhibitors of the type associated with chemical pretreatments (Kumar et al., 2009). In contrast, measurements showed that milling decreased macroporosity level, a phenomenon that was no doubt responsible for the lowered fiber degradation and thus fermentability of sample B.

Previous studies comparing the degradability of lignocellulosic substrates showed a positive effect of pretreatment on the degradation performance of different microbial consortia. For instance, Wongwilaiwalin et al. (2013) reported an increase in the degradation of alkalipretreated rice straw, sugarcane bagasse and corn stover by two selected thermophilic consortia BGC-1 and CRC-1 (50 $\left.{ }^{\circ} \mathrm{C}\right)$. Compared to the raw substrate, Guo et al., (2011) also reported a 3.3-fold increase in the degradation of $\mathrm{NaOH}$-pretreated rice straw by the $\mathrm{MC} 1$ thermophilic consortium $\left(50^{\circ} \mathrm{C}\right)$ and the production of $2.72 \mathrm{~g} . \mathrm{L}^{-1}$ organic acids after 3 days. Similarly, Zhao et al. (2014) reported $75 \%$ degradation of alkali-pretreated rice straw by the BMC-9 consortium, which accumulated a maximum of $3.3 \mathrm{mg} \mathrm{VFA.L}{ }^{-1}$ after 12 days incubation at $60^{\circ} \mathrm{C}$. Although it is difficult to compare the bioconversion efficiency reported in studies applying different pretreatment protocols (different $\mathrm{NaOH}$ concentration, solids loadings, incubation period) and culture conditions (inocula, culture media, incubation temperature), it is clear that alkali-pretreatment enhances the accessibility of lignocellulose towards bacteria. In this respect, the results reported herein are consistent with previous data, although VFA production levels were much higher, probably because of the strict anaerobic conditions that were applied (static or anoxic conditions were used in previous studies). Indeed, strict anaerobic conditions prevent microbial VFA consumption. 
388

389

390

391

392

393

394

395

396

397

398

399

400

401

402

403

404

405

406

407

408

409

410

411

412

3.2.2. Enzymatic activity profiles and biomass composition during wheat straw degradation by RWS

Xylanase and CMCase activities were measured regularly over the 15-day incubation period (Figure 3). For xylanase activity, two distinct profiles can be distinguished. Fermentation of the dry milled samples, A and B, procured maximum activities of $0.61 \pm 0.14 \mathrm{UA} \cdot \mathrm{mL}^{-1}$ and $0.81 \pm 0.11$ UA. $\mathrm{mL}^{-1}$, respectively, after 5 and 7 days of incubation. Thereafter, the activities remained stable. In contrast, the dry milled, chemically-pretreated samples, C and D, procured maximum enzyme activities after just 3 days of incubation, with the two activities attaining approximately 1.2 UA.mL ${ }^{-1}$. Thereafter, the activities decreased slightly (Figure 3A).

Correlating this data with the dynamics of hemicellulose degradation (Supplementary data and Figure 3C) revealed that the highest hemicellulose degradation rates (Figure 3C) coincided with increasing xylanase activity. For chemically-treated samples, measurements performed at day 1 revealed that xylanase levels were quite low, although hemicellulose degradation had already started, suggesting that the chemical pretreatment had already degraded the xylans, producing xylo-oligosaccharides. This observation is consistent with the release of free sugars observed after $24 \mathrm{~h}$ presoaking during macroporosity measurements. Comparing xylanase activity profiles and hemicellulose degradation with those of CMCase and cellulose degradation revealed quite different trends (Figure 3B and 3D). CMCase activity remained low (approximately $0.05 \mathrm{UA} \cdot \mathrm{mL}^{-1}$ ) in all of the experiments, irrespective of pretreatment. Moreover, no reliable correlations between CMCase activity and cellulose degradation rates were evidenced, CMCase activity did appear to reach maximum levels earlier (around day 4) in the case of samples C and D, compared to A and B (peaking after day 5). Correspondingly, cellulose degradation rates were also reached earlier (around day 3 )

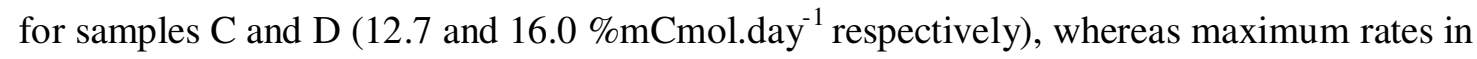
the case of $\mathrm{A}$ and $\mathrm{B}$ (7.5 and $5 \% \mathrm{mCmol}_{\text {day }}{ }^{-1}$ respectively) were achieved latter (about 5 
413

414

415

416

417

418

419

420

421

422

423

424

425

426

427

428

429

430

431

432

433

434

435

436

days). Taken together, our results indicate that hemicellulose and cellulose were degraded simultaneously. However, in the case of the chemically-pretreated samples the hemicellulose was probably solubilized and partially degraded, meaning that xylose was more readily available at early stage for bioconversion

To understand whether the different CMCase activity profiles reflect differential attack of the amorphous and crystalline fractions of cellulose, the evolution of crystallinity was investigated throughout the bioconversion of the four wheat straw samples. Figure 4 shows that crystallinity (LOI) evolved differently for each substrate. Since LOI is the ratio of crystalline versus amorphous cellulose, increases in LOI correlate with increased degradation of amorphous cellulose relative to the crystalline fraction. The microbial bioconversion of sample A was characterized by increasing LOI (from $0.73 \pm 0.04$ to $0.98 \pm 0.11$ ), whereas bioconversion sample B produced an opposite trend (decreased LOI, Fig. 4). However, in the chemically-pretreated samples (C and D) LOI remained mostly unchanged, suggesting that amorphous cellulose was preferentially degraded during substrate A fermentation, while the attack of the crystalline fraction of substrate B appeared to be facilitated by milling pretreatment. It is known that endocellulases mainly act on amorphous cellulose regions, while exocellulases act on crystalline regions (Lynd et al., 2002). Hence, simply measuring CMCase did not provide a complete view of cellulose degradation during RWS-mediated bioconversion. Nevertheless, our results indicate that RWS did possess a full cellulose arsenal, allowing it to degrade both amorphous and crystalline cellulose. Caution should nonetheless apply, because determining LOI using FT-IR only procures surface-related information, thus it is unclear whether FT-IR provides information on intra-fiber crystallinity. Further analyses at the metaproteomics will no doubt be needed to demonstrate whether RWS can adapt its enzymatic pool to a substrate structure. 
437

438

439

440

441

442

443

444

445

446

447

448

449

450

451

\section{Conclusion}

Dry milling combined with $\mathrm{NaOH}$ pretreatment enhanced wheat straw enzymatic hydrolysis and bioconversion using a microbial consortium RWS, leading to increased xylanase activity and VFA production rate. Compared to raw wheat straw, the optimal pretreatment was dry milling to $100 \mu \mathrm{m}$, combined to alkaline impregnation, which procured a greater than twofold increase in VFA production rate. Acetic, propionic and butyric acids were the main VFA produced by RWS, irrespective of the pretreatment method. An increase in butyric acid production was observed with chemically-pretreated substrates. Macroporosity appeared as the parameter that best predicts the biological acidogenic potential of RWS.

Acknowledgments. This research was supported by the French National Agency for Energy and the Environment (ADEME), the CEPIA department of INRA and the PROBIOS project funded by the Carnot Institute 3BCAR. We would like to acknowledge M. Abadie's important contribution in enzymatic analysis. M. Bounouba and E. Mangelle are also thanked for their technical support. 
452

453

454

455

456

457

458

459

460

461

462

463

464

465

466

467

468

469

470

471

\section{References}

1) Agbor, V.B., Cicek, N., Sparling, R., Berlin, A., Levin, D.B., 2011. Biomass pretreatment: fundamentals toward application. Biotechnol. Adv. 29, 675-685.

2) Agler, M.T., Wrenn, B.A., Zinder, S.H., Angenent, L.T., 2011. Waste to bioproduct conversion with undefined mixed cultures: the carboxylate platform. Trends Biotechnol. 29, 70-78.

3) Alvira, P., Tomás-Pejó, E., Ballesteros, M., Negro, M.J., 2010. Pretreatment technologies for an efficient bioethanol production process based on enzymatic hydrolysis: A review. Bioresour. Technol., Special Issue on Lignocellulosic Bioethanol: Current Status and Perspectives 101, 4851-4861.

4) Bali, G., Meng, X., Deneff, J.I., Sun, Q., Ragauskas, A.J., 2015. The effect of alkaline pretreatment methods on cellulose structure and accessibility. Chem. Sus. Chem. 8, 275-279.

5) Barakat, A., Chuetor, S., Monlau, F., Solhy, A., Rouau, X., 2014. Eco-friendly dry chemomechanical pretreatments of lignocellulosic biomass: Impact on energy and yield of the enzymatic hydrolysis. Appl. Energy 113, 97-105.

6) Barakat, A., de Vries, H., Rouau, X., 2013. Dry fractionation process as an important step in current and future lignocellulose biorefineries: a review. Bioresour. Technol. 134, 362-373.

7) Cavaillé, L., Grousseau, E., Pocquet, M., Lepeuple, A.-S., Uribelarrea, J.-L., HernandezRaquet, G., Paul, E., 2013. Polyhydroxybutyrate production by direct use of waste activated sludge in phosphorus-limited fed-batch culture. Bioresour. Technol. 149, 301-309. 
472 8) De Souza, A.C., Rietkerk, T., Selin, C.G.M., Lankhorst, P.P., 2013. A robust and universal

473 NMR method for the compositional analysis of polysaccharides. Carbohydr. Polym. 95, 657474663.

475 9) Guillon, F., Auffret, A., Robertson, J.A., Thibault, J.-F., Barry, J.-L., 1998. Relationships

476 between physical characteristics of sugar-beet fibre and its fermentability by human faecal

477 flora. Carbohydr. Polym. 37, 185-197.

478 10) Guo, P., Mochidzuki, K., Cheng, W., Zhou, M., Gao, H., Zheng, D., Wang, X., Cui, Z.,

479 2011. Effects of different pretreatment strategies on corn stalk acidogenic fermentation using 480 a microbial consortium. Bioresour. Technol. 102, 7526-7531.

481 11) Hendriks, A.T.W.M., Zeeman, G., 2009. Pretreatments to enhance the digestibility of 482 lignocellulosic biomass. Bioresour. Technol. 100, 10-18.

12) Jaros, A.M., Rova, U., Berglund, K.A., 2013. Acetate adaptation of Clostridia

484 tyrobutyricum for improved fermentation production of butyrate. Springerplus. 2: 47.

485

486

487

488

489

490

491

492

493

13) Jönsson, L.J., Alriksson, B., Nilvebrant, N.-O., 2013. Bioconversion of lignocellulose:

inhibitors and detoxification. Biotechnol. Biofuels 6, 16 .

14) Kaar, W.E., Holtzapple, M.T., 2000. Using lime pretreatment to facilitate the enzymic hydrolysis of corn stover. Biomass Bioenergy 18, 189-199.

15) Karp, E.M., Resch, M.G., Donohoe, B.S., Ciesielski, P.N., O’Brien, M.H., Nill, J.E., Mittal, A., Biddy, M.J., Beckham, G.T., 2015. Alkaline pretreatment of switchgrass. ACS Sustain. Chem. Eng. 3: 1479-1491.

16) Kim, S., Dale, B.E., 2004. Global potential bioethanol production from wasted crops and crop residues. Biomass Bioenergy 26, 361-375. 
494

495

496

497

498

499

500

501

502

503

504

505

506

507

508

509

510

511

512

513

514

515

17) Kumar, P., Barrett, D.M., Delwiche, M.J., Stroeve, P., 2009. Methods for pretreatment of lignocellulosic biomass for efficient hydrolysis and biofuel production. Ind. Eng. Chem. Res. 48, 3713-3729.

18) Lazuka, A., Auer, L., Bozonnet, S., Morgavi, D.P., O’Donohue, M., Hernandez-Raquet, G., 2015. Efficient anaerobic transformation of raw wheat straw by a robust cow rumenderived microbial consortium. Bioresour. Technol. 196, 241-249.

19) Liu, X., Yang, S.-T., 2006. Kinetics of butyric acid fermentation of glucose and xylose by Clostridium tyrobutyricum wild type and mutant. Process Biochem. 41, 801-808.

20) Lynd, L.R., Weimer, P.J., van Zyl, W.H., Pretorius, I.S., 2002. Microbial cellulose utilization: fundamentals and biotechnology. Microbiol. Mol. Biol. Rev. 66, 506-577.

21) Mathew, A.K., Chaney, K., Crook, M., Humphries, A.C., 2011. Alkaline pre-treatment of oilseed rape straw for bioethanol production: evaluation of glucose yield and pre-treatment energy consumption. Bioresour. Technol. 102, 6547-6553.

22) Miao, Z., Grift, T.E., Hansen, A.C., Ting, K.C., 2011. Energy requirement for comminution of biomass in relation to particle physical properties. Ind. Crops Prod. 33, 504513.

23) Monlau, F., Barakat, A., Steyer, J.P., Carrere, H., 2012. Comparison of seven types of thermo-chemical pretreatments on the structural features and anaerobic digestion of sunflower stalks. Bioresour. Technol. 120, 241-247.

24) Mosier, N., Wyman, C., Dale, B., Elander, R., Lee, Y.Y., Holtzapple, M., Ladisch, M., 2005. Features of promising technologies for pretreatment of lignocellulosic biomass.

Bioresour. Technol. 96, 673-686. 
516

517

518

519

520

521

522

523

524

525

526

527

528

529

530

531

532

533

534

535

25) Palmowski, L.M., Müller, J.A., 2000. Influence of the size reduction of organic waste on their anaerobic digestion. Water Sci. Technol. 41, 155-162.

26) Raganati, F., Procentese, A., Olivieri, G., Russo, M.E., Salatino, P., Marzocchella, A., 2014. MFA of clostridium acetobutylicum pathway: The role of glucose and xylose on the acid formation/uptake. Chem. Eng. Trans. 38, 337-342.

27) Robertson, J.A., de Monredon, F.D., Dysseler, P., Guillon, F., Amado, R., Thibault, J.-F., 2000. Hydration properties of dietary fibre and resistant starch: a European collaborative study. LWT - Food Sci. Technol. 33, 72-79.

28) Robertson, J.A., Eastwood, M.A., 1981. A method to measure the water-holding properties of dietary fibre using suction pressure. Br. J. Nutr. 46, 247-255.

29) Tollier, M.T., Robin, J.P. (1979) Adaptation de la méthode à l'orcinol sulfurique au dosage automatique des oses neutres et totaux, Ann. Technol. Agric. 28, 1-15

30) Torella, J.P., Ford, T.J., Kim, S.N., Chen, A.M., Way, J.C., Silver, P.A. 2013. Tailored fatty acid synthesis via dynamic control of fatty acid elongation. PNAS, 110:11290-5.

31) Wyman C.E. 2007What is (and is not) vital to advancing cellulosic ethanol. Trends Biotechnol. 25: 153-157

32) Wongwilaiwalin, S., Laothanachareon, T., Mhuantong, W., Tangphatsornruang, S., Eurwilaichitr, L., Igarashi, Y., Champreda, V., 2013. Comparative metagenomic analysis of microcosm structures and lignocellulolytic enzyme systems of symbiotic biomass-degrading consortia. Appl. Microbiol. Biotechnol. 97, 8941-8954. 
536 33) Zhao, H., Yu, H., Yuan, X., Piao, R., Li, H., Wang, X., Cui, Z., 2014. Degradation of

537 lignocelluloses in rice straw by BMC-9, a composite microbial system. J. Microbiol.

538 Biotechnol. 24, 585-724.

539 34) Zhao, Y., Wang, Y., Zhu, J.Y., Ragauskas, A., Deng, Y., 2008. Enhanced enzymatic

540 hydrolysis of spruce by alkaline pretreatment at low temperature. Biotechnol. Bioeng. 99,

$541 \quad 1320-1328$.

542 
543

544

545

546

547

548

549

550

551

552

553

554

555

556

557

558

559

560

561 562 biological replicates.

563 Figure. 4. Lateral order index (LOI) profiles during fermentation of pretreated wheat straw by 564

\section{Figure captions}

Figure 1. Characterization of the pretreated wheat straw substrates. (A) Lateral order index (LOI). (B) Macroporosity estimated at $1 \mu \mathrm{m}$-pore volume determined as the difference between total and inferior-to-1 $\mu \mathrm{m}$ pore volume. (C) Biochemical composition of wheat straw (Cellulose $-\mathrm{C}$, hemicellulose $-\mathrm{H}$ and lignin $-\mathrm{L}$ ). The types of pretreatment are indicated by the bar colors as in A. (D) Reducing sugars liberated from wheat straw by the saccharification test performed under standard conditions (Cellulase, 20 FPU.L ${ }^{-1}, \beta$-glucosidase 81 U.mL ${ }^{-1}, 72 \mathrm{~h}$, $\left.50^{\circ} \mathrm{C}, \mathrm{pH} 5\right)$. Error bars indicate the standard deviation of the mean of three technical replicates. Different lowercase letters indicate differences within a treatment (one-way ANOVA, $\mathrm{P}<0.05)$.

Figure 2. Wheat straw transformation kinetics by RWS incubated with the four pretreated wheat straws. (A) Holocellulose degradation and (C) Holocellulose degradation rate. (B) Specific VFA production and (D) Specific VFA production rate. Experimental points and smoothed curves are presented with error bars corresponding to the standard deviation of the mean of two biological replicates.

Figure 3. Kinetics of enzymatic activity and polysaccharide degradation throughout the fermentation of pretreated-wheat straw by a RWS consortium. Xylanase (A) and CMCase (B) activity and cellulose (C) and hemicellulose (D) degradation rates. Experimental points and smoothed curves are presented with error bars corresponding to the standard deviation of two a RWS consortium. Error bars correspond to the standard deviation of 2 biological duplicates. 


\section{Figure 1}

A

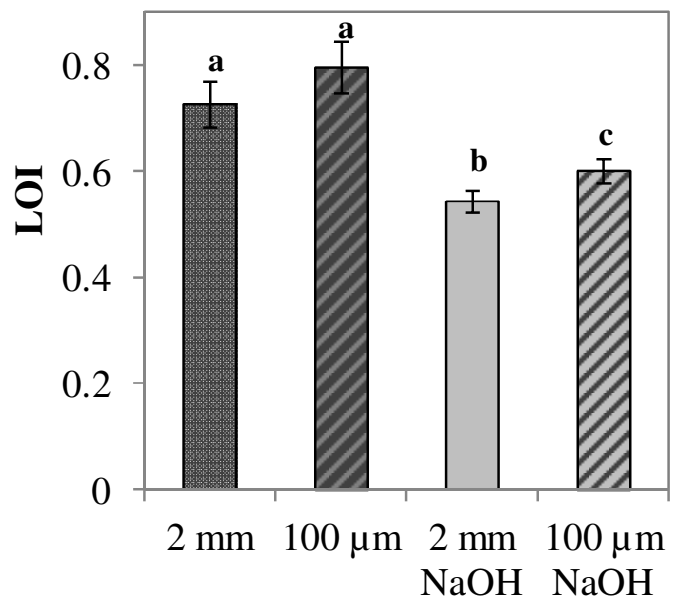

B

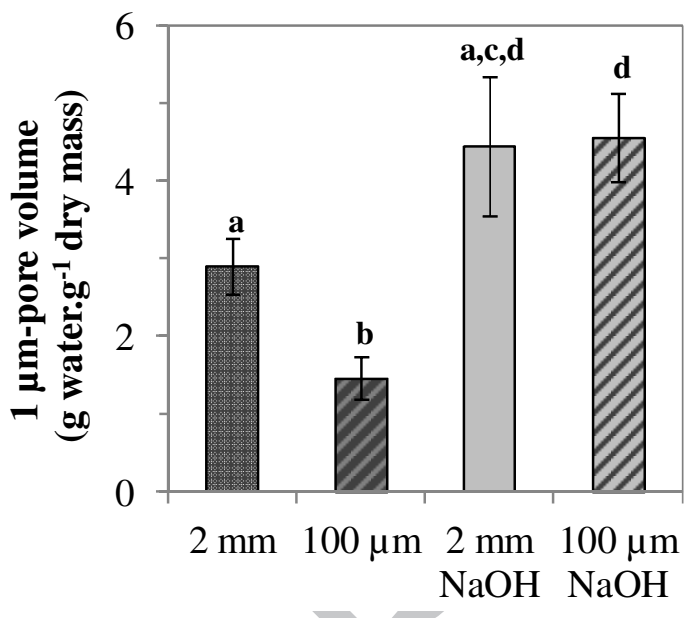

D

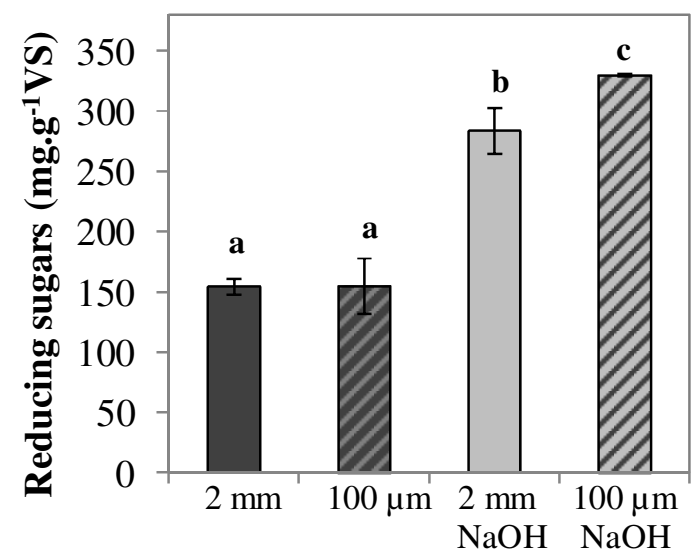

567

$\mathrm{C}$

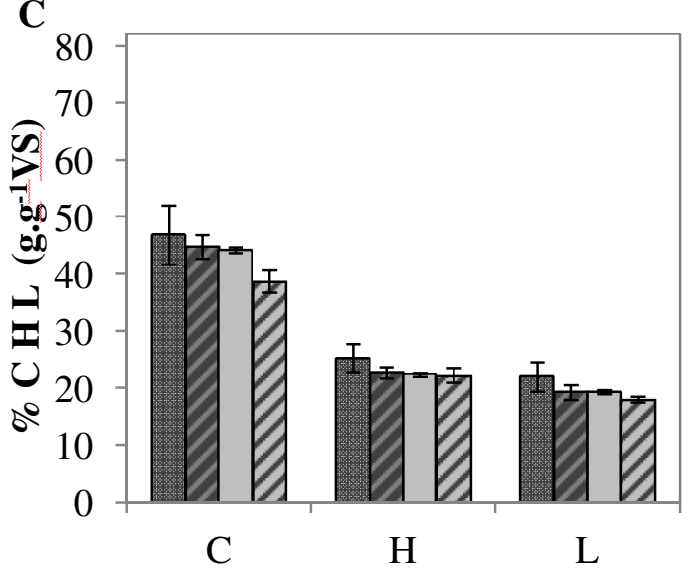

568 


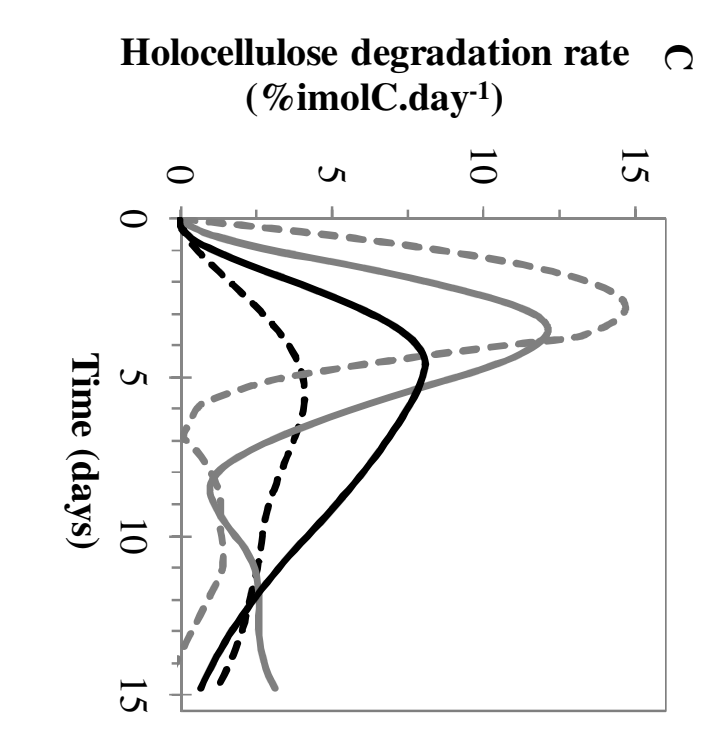

Holocellulose degradation
(\%

$1 \stackrel{0}{\stackrel{0}{0}}$

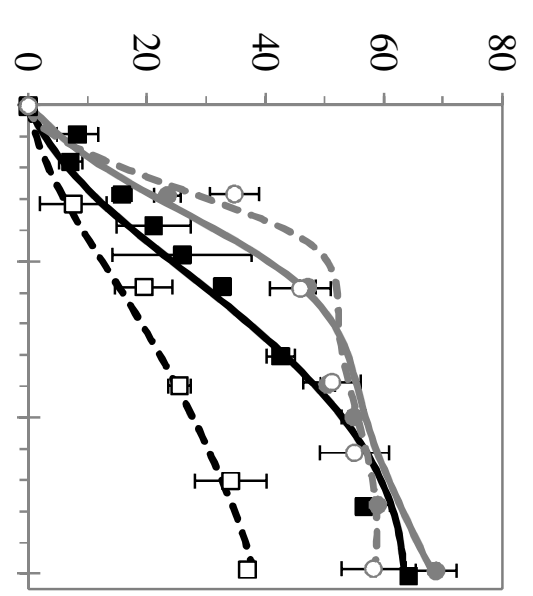
specific VFA production rate
(Cmol.Cmol iHolo ${ }^{-1}$.day $\left.{ }^{-1}\right)$

- specific VFA production

○ (Cmol.Cmol iHolo-1)
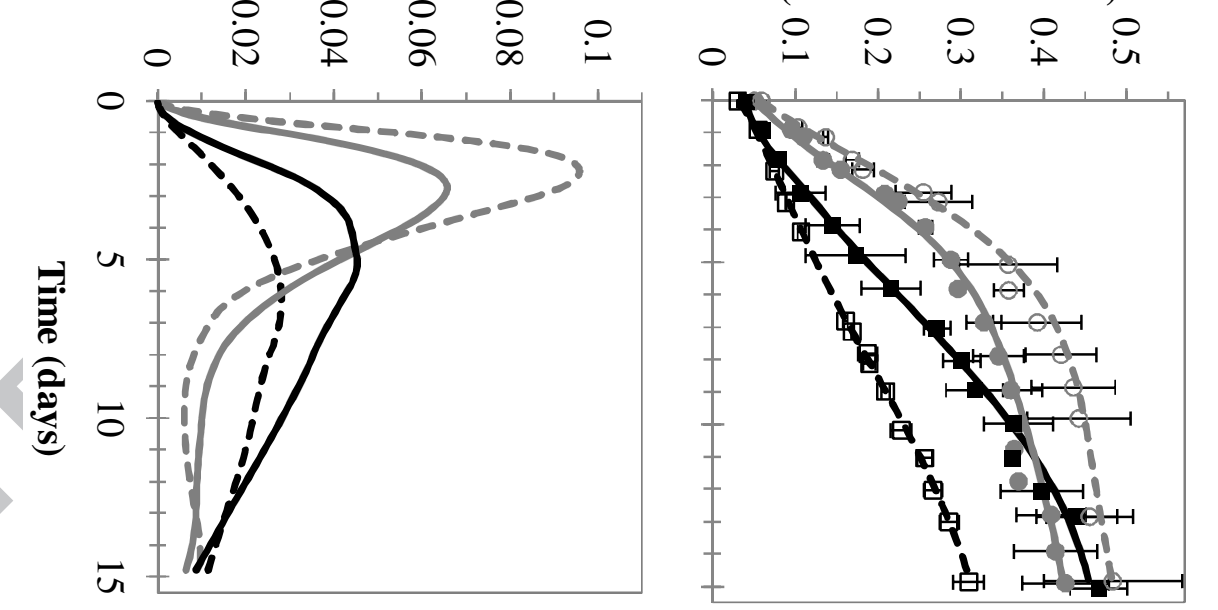

$\infty$ 

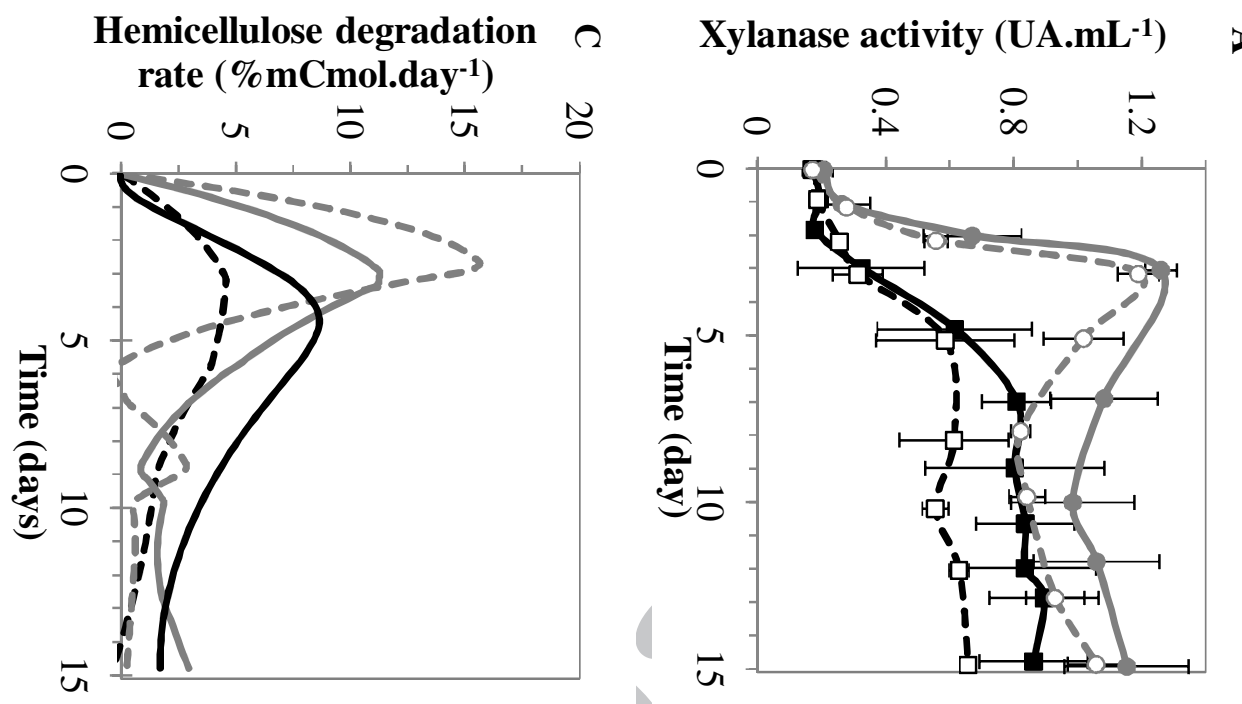

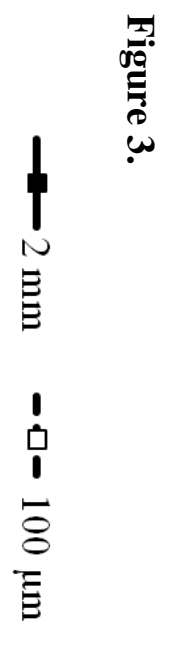

Cellulose degradation rate $\theta$ (\% mCmol.day $\left.{ }^{-1}\right)$
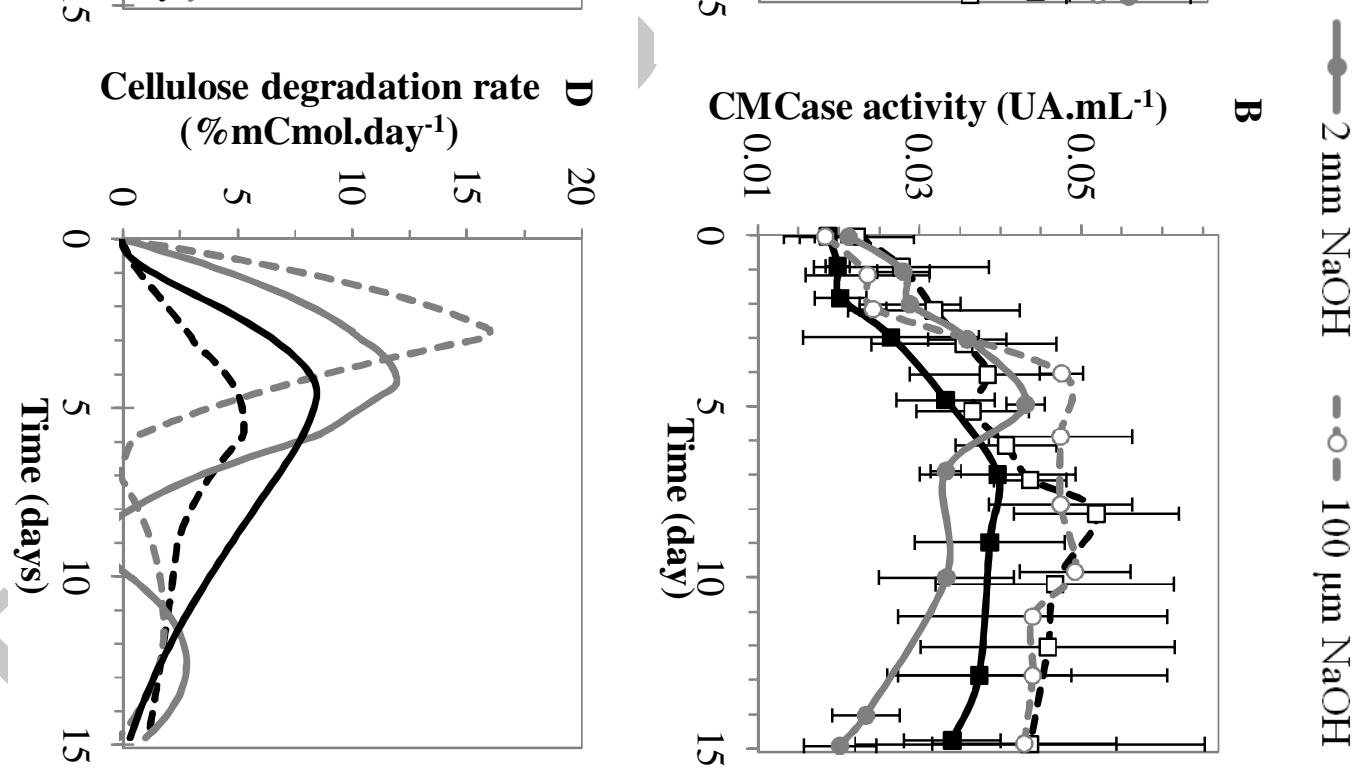
$577 \quad$ Figure 4.

578

$$
\begin{array}{ll}
\rightarrow-2 \mathrm{~mm} & -\square-100 \mu \mathrm{m} \\
\rightarrow 2 \mathrm{~mm} \mathrm{NaOH} & --0-100 \mu \mathrm{m} \mathrm{NaOH}
\end{array}
$$

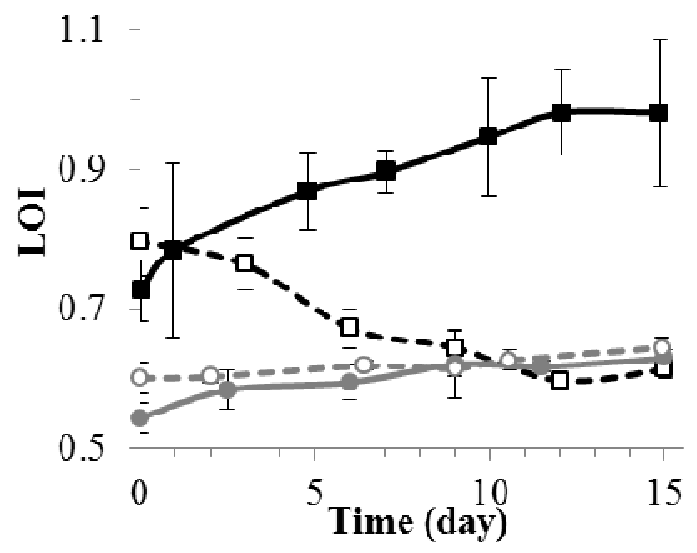

579

580 
581 Tables

582 Table 1: Size and energy consumption of the four types of wheat straw pretreatment.

\begin{tabular}{|c|c|c|c|}
\hline \multicolumn{2}{|c|}{ Pretreatment } & Size $(\mu \mathrm{m}), \mathrm{D} 50$ & Energy $\left(\mathrm{kJ} \cdot \mathrm{kg}^{-1}\right)$ \\
\hline A & $2 \mathrm{~mm}$ & - & 223.34 \\
\hline B & $100 \mu \mathrm{m}$ & $115.87 \pm 3.24$ & 635.23 \\
\hline $\mathrm{C}$ & $2 \mathrm{~mm}-\mathrm{NaOH}$ & - & 223.34 \\
\hline $\mathrm{D}$ & $100 \mu \mathrm{m}-\mathrm{NaOH}$ & $91.54 \pm 2.24$ & 327.45 \\
\hline
\end{tabular}

583

584 
Table 2: Product concentrations and metabolic yields after a 15-day fermentation of the pretreated wheat straw substrates by a RWS microbial consortium.

\section{(A) 2 mm \\ (B) $100 \mu \mathrm{m}$ \\ (C) $2 \mathrm{~mm} \mathrm{NaOH}$ \\ (D) $100 \mu \mathrm{m} \mathrm{NaOH}$}

\begin{tabular}{|c|c|c|c|c|}
\hline $\begin{array}{l}\text { VFA yield* } \\
\left(\text { g eq AA.g }^{-1}\right)\end{array}$ & $0.61 \pm 0.07$ & $0.77 \pm 0.03$ & $0.70 \pm 0.07$ & $0.83 \pm 0.14$ \\
\hline $\begin{array}{l}\mathrm{CO}_{2} \text { yield* } \\
\left(\mathrm{g} \mathrm{CO}_{2} \cdot \mathrm{g}^{-1}\right)\end{array}$ & $0.26 \pm 0.03$ & $0.47 \pm 0.02$ & $0.41 \pm 0.07$ & $0.58 \pm 0.15$ \\
\hline $\begin{array}{c}\mathrm{H}_{2} \text { yield* } \\
\left(\mathrm{mg} \mathrm{H}_{2} \cdot \mathrm{g}^{-1}\right)\end{array}$ & $0.55 \pm 0.19$ & $1.52 \pm 0.20$ & $2.70 \pm 0.47$ & $3.25 \pm 0.31$ \\
\hline $\begin{array}{l}\text { Time at maximum } \\
\text { VFA prod. rate } \\
\text { (days) }\end{array}$ & 5.2 & 6.0 & 2.9 & 2.2 \\
\hline $\begin{array}{l}\text { Max VFA prod. rate } \\
\left(\mathrm{mCmol} . \mathrm{L}^{-1} \cdot \text { day }^{-1}\right)\end{array}$ & $25.6 \pm 1.0$ & $13.4 \pm 0.14$ & $35.6 \pm 6.0$ & $43.4 \pm 4.1$ \\
\hline $\begin{array}{l}\text { VFA concentration } \\
\text { at max VFA prod. } \\
\text { rate }\left(\mathrm{mCmol} . \mathrm{L}^{-1}\right)\end{array}$ & $109.0 \pm 20.8$ & $72.2 \pm 7.4$ & $100.1 \pm 4.2$ & $94.2 \pm 4.4$ \\
\hline $\begin{array}{c}\text { Final VFA prod. } \\
\left(\mathrm{mCmol} . \mathrm{L}^{-1}\right)\end{array}$ & $226.5 \pm 21.1$ & $149.0 \pm 3.5$ & $228.3 \pm 22.1$ & $217.1 \pm 20.9$ \\
\hline$\% \mathrm{AA}(\% \mathrm{Cmol})$ & $65.6 \pm 3.9$ & $50.8 \pm 2.6$ & $38.6 \pm 3.6$ & $34.3 \pm 1.2$ \\
\hline$\% \mathrm{PA}(\% \mathrm{Cmol})$ & $20.5 \pm 3.4$ & $24.7 \pm 0.4$ & $24.0 \pm 7.6$ & $22.3 \pm 6.1$ \\
\hline$\% \mathrm{BA}(\% \mathrm{Cmol})$ & $10.0 \pm 2.9$ & $17.8 \pm 2.3$ & $28.0 \pm 2.1$ & $33.1 \pm 6.5$ \\
\hline$\% \mathrm{VA}(\% \mathrm{Cmol})$ & $3.8 \pm 3.1$ & $4.9 \pm 0.3$ & $5.5 \pm 0.2$ & $6.0 \pm 0.6$ \\
\hline
\end{tabular}

* Metabolic yield, against consumed substrate

588

589 


\section{Highlights}

591

592

593

594

595

596
- Dry chemo-mechanical pretreatments impact biomass crystallinity and macroporosity.

- Dry chemo-mechanical pretreatment increased the carboxylate production rate by RWS.

- Dry chemo-mechanical pretreated biomass enhances the microbial xylanase activity.

- Initial biomass macroporosity correlated with the biological acidogenic potential. 